\title{
Conuses and discontinuities: To be or not to be in double-outlet right ventricle
}

\author{
Henry L. Walters III, MD
}

\author{
From the Department of Cardiovascular Surgery, Children's Hospital of Michigan; and the Department of \\ Surgery, Wayne State University School of Medicine, Detroit, Mich. \\ Disclosures: Author has nothing to disclose with regard to commercial support. \\ Received for publication April 4, 2017; accepted for publication April 5, 2017; available ahead of print May 3 , \\ 2017. \\ Address for reprints: Henry L. Walters III, MD, Department of Cardiovascular Surgery, Children's Hospital of \\ Michigan, 3901 Beaubien Blvd, Detroit, MI 48201 (E-mail: hwalters@dmc.org). \\ J Thorac Cardiovasc Surg 2017;154:605-6 \\ $0022-5223 / \$ 36.00$ \\ Copyright (c) 2017 by The American Association for Thoracic Surgery \\ http://dx.doi.org/10.1016/j.jtcvs.2017.04.006
}

The marked degree of variability in infundibular morphology, from complete muscular conuses bilaterally $(23 \%)$ to some degree of semilunar-to-atrioventricular valvar continuity (49\%), that Ebadi and colleagues ${ }^{1}$ found in 100 specimens of hearts with double-outlet right ventricle (DORV) and describe in this issue of the Journal led to their conclusion that the presence of conuses with discontinuity should not be a required diagnostic feature for DORV.

With its broad spectrum of phenotypes, DORV occupies the anatomic continuum between tetralogy of Fallot and transposition of the great arteries. How does one use precise anatomic criteria to distinguish between DORV, with its tunnel repair, and a potential masquerader such as tetralogy of Fallot, that requires only a flat patch? Ebadi and colleagues ${ }^{1}$ accurately state, "Recognition of this difference (in surgical approach) provides a pragmatic solution to defining DORV." Such a definition, however, despite being pragmatic, unfortunately violates one of the rules of congenital cardiac nomenclature: "The definition of a congenital cardiac malformation is never based upon its surgical repair." 2 Congenital cardiac malformations should be identifiable regardless of whether a surgical intervention is undertaken.

Because Ebadi and colleagues ${ }^{1}$ use a $75 \%$ rule in their study, it is likely that they subscribe to the Definitions Working Group-International Society for the Nomenclature of Pediatric and Congenital Heart Disease (DWG-ISNPCHD) definition of DORV: “A congenital cardiovascular malformation in which both great arteries arise entirely or predominantly from the morphologically right ventricle." 3 Does this definition of DORV distinguish true cases from likely impostors? In the clinical realm, the determination of $60 \%$ versus $80 \%$ override or predominant versus nonpredominant right ventricular origin is dependent on perspective. When viewed through the tricuspid valve, the degree of aortic override may at times appear to demand a tunnel repair. But when viewed through a right ventriculotomy incision, the degree of overriding may be less extreme, allowing the use of a flat patch repair.

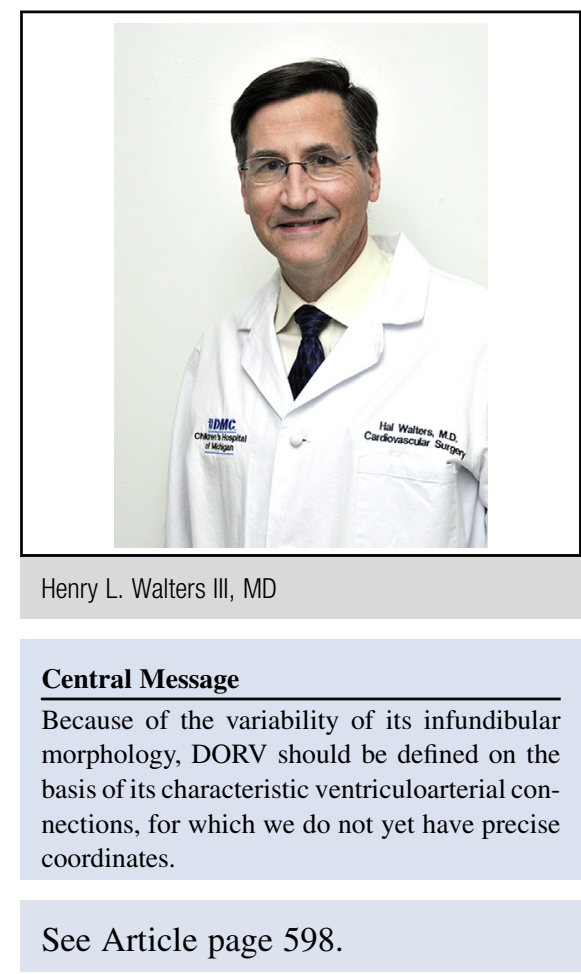

The perspective through which one views the cardiac anatomy does make a difference. The examination of pathologic specimens in this study may create a selection bias, because all the patients died and because at least $9 \%$ of the cases were functionally univentricular. Although this possible limitation may skew the proportions of the various DORV phenotypes that Ebadi and colleagues ${ }^{1}$ report relative to clinical DORV series, their basic inference remains sound. Because Ebadi and colleagues ${ }^{1}$ found that DORV does frequently coexist with semilunar-to-atrioventricular valvular continuity, however, it would be interesting to know how many specimens with 2 apparently functional ventricles and subaortic ventricular septal defect, had aortic-to-mitral continuity. This is a potential paradox since the DORV-subaortic ventricular septal defect phenotype is the one most commonly reported in surgical series, ${ }^{4}$ and in my experience it is almost invariably associated with aortic-to-mitral discontinuity.

The examination of pathologic specimens can also be associated with important interobserver variability. In panel $B$ of Figure 2 in the article by Ebadi and colleagues, ${ }^{1}$ the aortic root mostly overrides a remarkably hypertrophied septum, rather than the right ventricle. After enlargement 
of the restrictive ventricular septal defect, the placement of a flat patch on the right side of the ventricular septum with some anterior angulation to the aortic valve is reasonable, rather than creating a tunnel. If a subaortic conus were present in this same specimen, the aortic valve would have been displaced superiorly and anteriorly, requiring a tunnel patch configuration. Without a more precise definition for DORV, different observers can legitimately arrive at different interpretations when examining the same pathologic specimen.

This study is a convincing morphological argument that DORV should be defined on the basis of its characteristic ventriculoarterial connections, without an absolute requirement for conuses or discontinuity. Some authors, however, who choose to add conus and discontinuity riders to their definition of DORV do so not because they consider it to be an inviolable law of nature but because they consider it a useful morphologic and echocardiographic rule. DORV is a descriptive term that is not used to name a discrete congenital cardiac malformation; rather, it is used to corral a broad range of phenotypes in which the arterial roots take origin wholly or predominantly from the right ventricle. As such, DORV has been difficult to define with precision, allowing legitimate cases to slip out between the fence rails and impostors to slip in. This is true whether conuses and discontinuities are to be or not to be an integral part of one's definition of DORV.

\section{References}

1. Ebadi A, Spicer DE, Backer C, Fricker FJ, Anderson RH. Double-outlet right ventricle revisited. J Thorac Cardiovasc Surg. 2017;154:598-604.

2. Walters HL, Colan SD. Defining terms in lists of nomenclature. In: Barach PR, Jacobs JP, Lipshultz SE, Laussen PC, eds. Pediatric and congenital cardiac disease: Volume 1: outcomes analysis. London: Springer-Verlag; 2015:51-61.

3. World Health Organization. ICD-11 Beta Draft (Mortality and Morbidity Statistics): double outlet right ventricle. Available at: http://apps.who.int/classifications/icd11/ browse/l-m/en\#http $\% 3 \mathrm{a} \% 2 \mathrm{f} \% 2$ fid.who.int $\% 2$ ficd $\% 2$ fentity $\% 2$ f 141717788 . Accessed March 4, 2017.

4. Musumeci F, Shumway S, Lincoln C, Anderson RH. Surgical treatment for double-outlet right ventricle at the Brompton Hospital, 1973 to 1986. J Thorac Cardiovasc Surg. 1988;96:278-87. 